\title{
STUDY THE EFFECT OF NUMBER OF NOZZLE ON OPTICAL AND STRUCTURAL PROPERTIES OF SNO2 FILMS GROWN BY (APCVD)
}

\author{
Orass A. Hussein ${ }^{1}$, Nathera A. Ali $^{2}$
}

Abstract- The atmospheric chemical vapor deposition (APCVD) technique was used for the synthesis of the tin oxide (SnO2) thin films. Our study focus on prepare $\mathrm{SnO} 2$ films with high optical quality by using various number of capillary tube as deposition nozzle $(1,3,5,7)$. The optical transmittance was measured by UV-VIS spectrophotometer. X-ray diffraction (XRD) was employed to find the crystallite size. (XRD) studies show that (110) peak has strongest intensity in all films, average grain size $(13.56 \mathrm{~nm})$ was measured by using Debye Scherrer's formula. maximum transmission can be measured is $(95 \%)$ at three capillary tube. (AFM) where use to analyze the morphology of the tin oxides surface. Roughness and average grain size for different number of capillary tube have been investigated The optical properties of the $\mathrm{SnO} 2$ thin films were determined using UV-Visible spectrum for the prepared $\mathrm{SnO2}$ thin films.

Keywords - APCVD ; SnO2 thin film; XRD; optical properties; AFM.

\section{Introduction}

$\mathrm{SnO} 2$ is chemically inert, mechanically hard, and can resist high temperatures [1]. tin Oxide thin films are n-type semiconductors with low electrical resistance with high optical transparency in the visible range[3]. It is used as a window layer in solar cells [2-3], heat reflectors in solar cells [4], various gas sensors [5], Tin oxide is a wide band gap $(\approx 4 \mathrm{eV})$ and indirect band gap (of about $2.6 \mathrm{eV}$ ) nonstoichiometric semiconductor.

Thin oxide films have been deposited using different techniques, such as thermal evaporation [6,7], sputtering [713], chemical vapour deposition [6,14-16], sol-gel dip coating [6,13,17], painting [6,13,18], spray pyrolysis [6,8,16,19-24], hydrothermal method [25] and pyrosol deposition [6,16,26-28]. In this research, SnO2 thin film was preparing by using atmospheric chemical vapor deposition (APCVD) technique. A SnO2 thin film CVD process normally consist of four basic ingredients: vapor of the so-called 'precursor' which is a tin-containing molecule (i. e. $\mathrm{SnCl4}$ ), an oxygen source (i. e. $\mathrm{H} 2 \mathrm{O}$ vapor and/or O2), a carrier gas (i. e. N2 or Ar) and a substrate. When these four ingredients are brought together inside a CVD reactor a thin film can be synthesized.

\section{EXPERIMENTAL DETAILS}

The substrate which are glass were cleaned first by dipping in distilled water to remove the dust and then they were ultrasonically cleaned in ethanol (purity 98\%) for at least $15 \mathrm{~min}$. APCVD is basically a chemical process which consists of heating hydrated tin dichloride $\left(\mathrm{SnCl}_{2} .2 \mathrm{H}_{2} \mathrm{O}\right)$ under oxygen flow. The vapor of the precursor reacts with oxygen then carried on the glass substrate through different nozzle by the $\mathrm{O}_{2}$ gas. $\mathrm{N}_{2}$ gas use to prevent the oxidation of substrate during heating. The substrate temperature (working temperature) was $450{ }^{\circ} \mathrm{C}$.

Table -1: The operating parameters for (APCVD) system

\begin{tabular}{|c|c|}
\hline \multicolumn{2}{|c|}{ Deposition parameters of tin oxide film } \\
\hline Thin film & $\mathrm{SnO2}$ \\
\hline
\end{tabular}

1 Department of Physic, Samarra University, Samarra, Iraq

2 Department of Physic, Baghdad University, Baghdad, Iraq 


\begin{tabular}{|c|c|}
\hline Substrate & Glass \\
\hline Temperature (0C) & 450 \\
\hline O2 gas flow rate & $0.5 \mathrm{~L} / \mathrm{min}$ \\
\hline N2 gas flow rate & $0.5 \mathrm{~L} / \mathrm{min}$ \\
\hline No. capillary tube & $1,3,5,7$ \\
\hline Time deposition & $1 \mathrm{sec}$ \\
\hline
\end{tabular}

\section{RESULTS AND DISCUSSION}

\section{A. Structural properties -}

The XRD patterns recorded for $\mathrm{SnO} 2$ thin films deposited by the APCVD technique as a function of the different nozzle that use to deposition thin film ( $\mathrm{A} 1=7, \mathrm{~A} 2=5, \mathrm{~A} 3=3, \mathrm{~A} 4=1$ capillary tubes). The $\mathrm{SnO} 2$ films deposited on glass substrate at temperature (450)0 C . The best nozzle is (A4=1 capillary tube) as shown in Fig. (1). The Max. Peak (110) at $2 \theta$ values of $26.36^{\circ}$. The average particle size (D) was estimated using the Scherrer equation:

$$
\mathrm{D}=0.9 \lambda / \beta \cos \theta
$$

where $\mathrm{D}$ is the crystallite size, $\lambda$ is the $\mathrm{X}$-ray wavelength, $\beta$ is the full width at half maximum of the diffraction peak, and $\theta$ is the Bragg diffraction angle of the diffraction peaks. Average grain size was found to be $(13.56 \mathrm{~nm})$.

The use of a different nozzles in the deposition process change the shape of the thin film due to the fact that the number of particles attached to the glass base will double and therefore the thickness of the thin film will change from thin to thick. This interpretation is consistent with the results $(76.4,195.8,123.5$, and $355.7 \mathrm{~nm})$ for (A4,A3, A2, and A1) nozzle respectively.

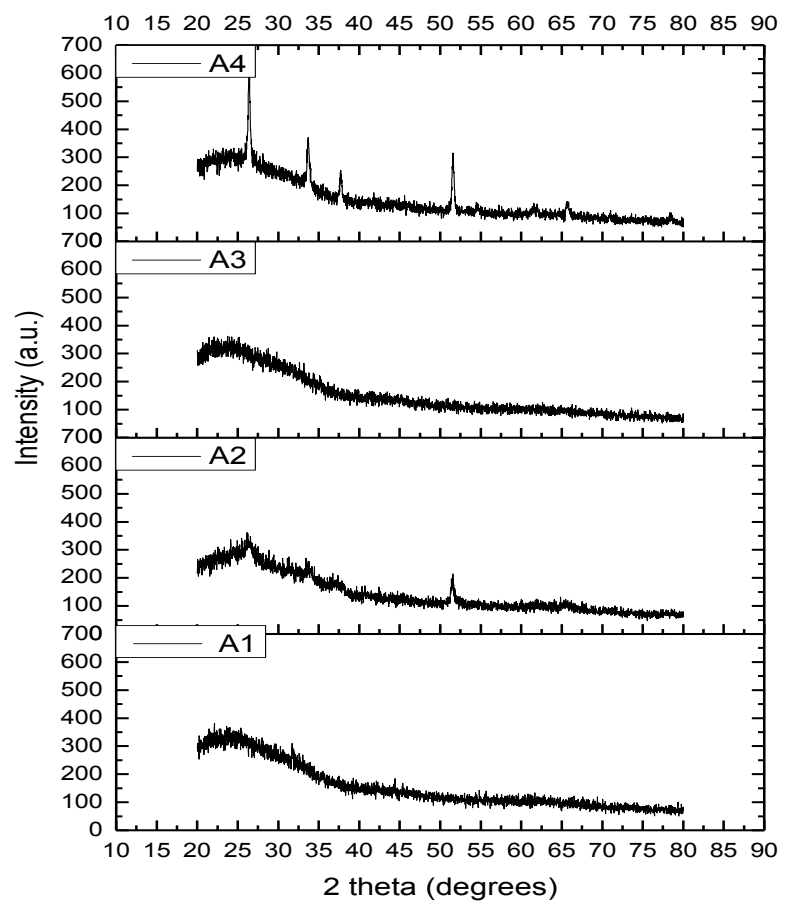

Figure 1. X-ray diffraction pattern for $\mathrm{SnO}_{2}$ film deposited on glass substrate at different nozzle

\section{B. Surface topography properties -}

The study of surface morphology of $\mathrm{SnO} 2$ thin films deposited by chemical vapor deposition method has been carried out using atomic force microscopy (AFM). We report the AFM images of $\mathrm{SnO} 2$ thin film in two \& three dimension 
view (2D\& 3D). In figure (2 ) compares typical morphology of the $\mathrm{SnO}_{2}$ sample (A1-A4) in two \& three dimension. It can be seen from fig. (2) that with increasing no. of capillary tube the degree of surface roughness decreases from $1.81 \mathrm{~nm}$ to $0.259 \mathrm{~nm}$.
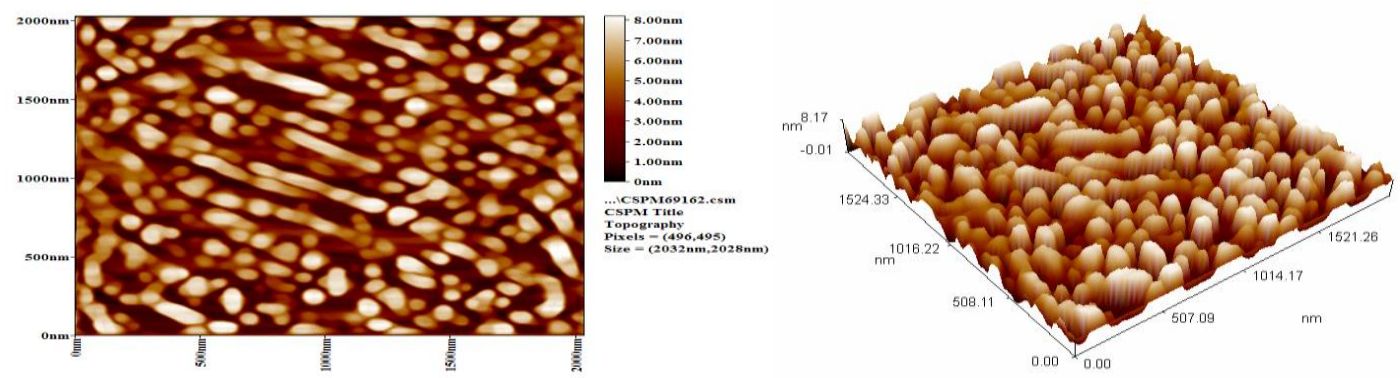

(A4) One capillary tubes
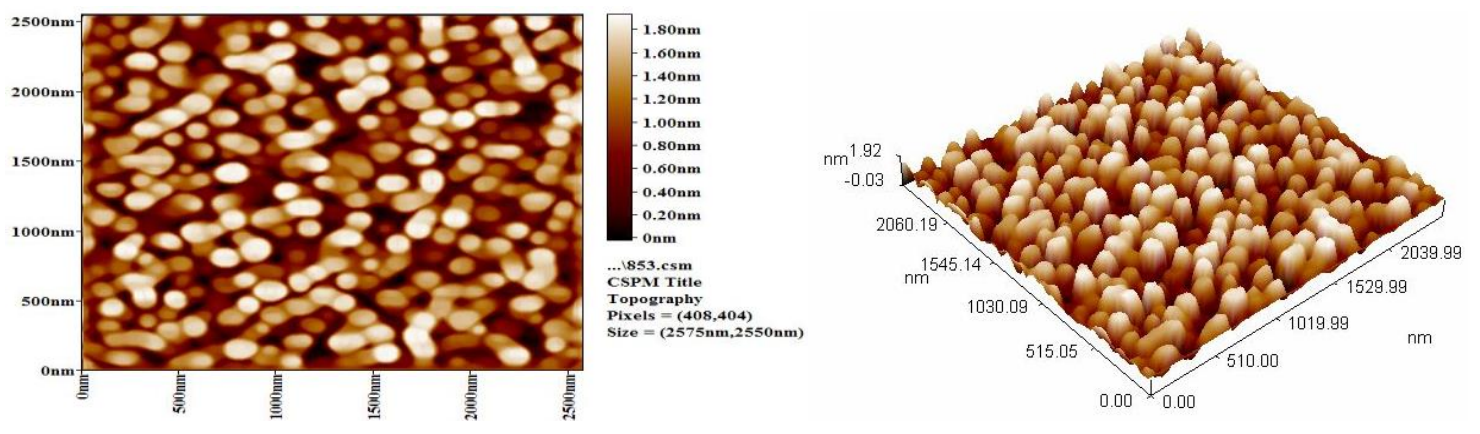

(A3) Three capillary tubes
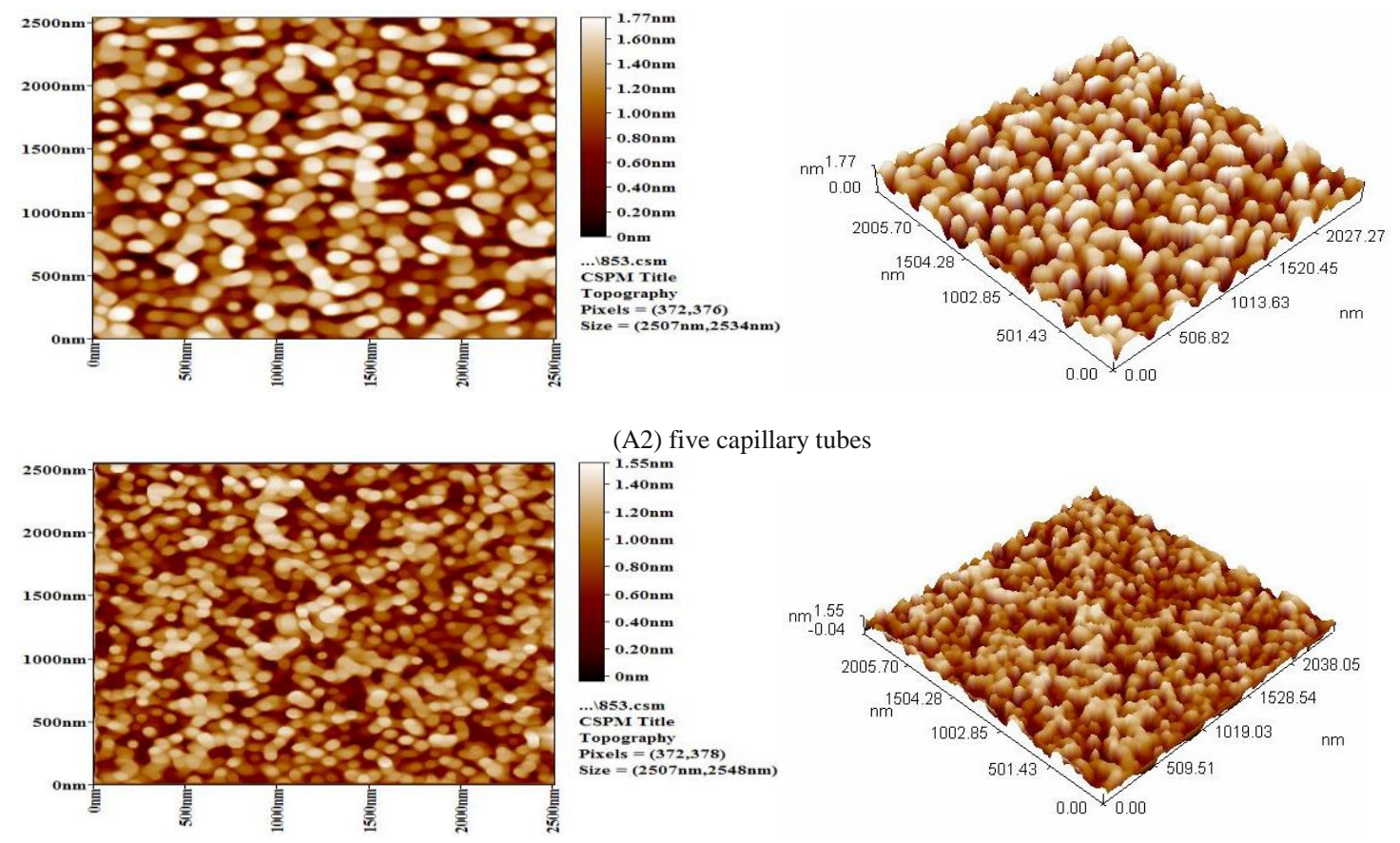

(A1) seven capillary tubes

Figure 2. AFM of $\mathrm{SnO}_{2}$ thin film for different nozzles

\section{Optical properties -}

Figure (3) shows the variation of transmittance ( $T$ ) with respect to the wavelength of $\mathrm{SnO}_{2}$ thin films with different no. of nozzle. The maximum transmittance is $95 \%, 90 \%, 84 \%$ and $80 \%$ (in visible range nm), respectively for A3, 
A2, A1 and A4 . The visible transmittance attained for the A3 film in this study is higher than the values reported for others (A1, A2, A4) tin oxide films.

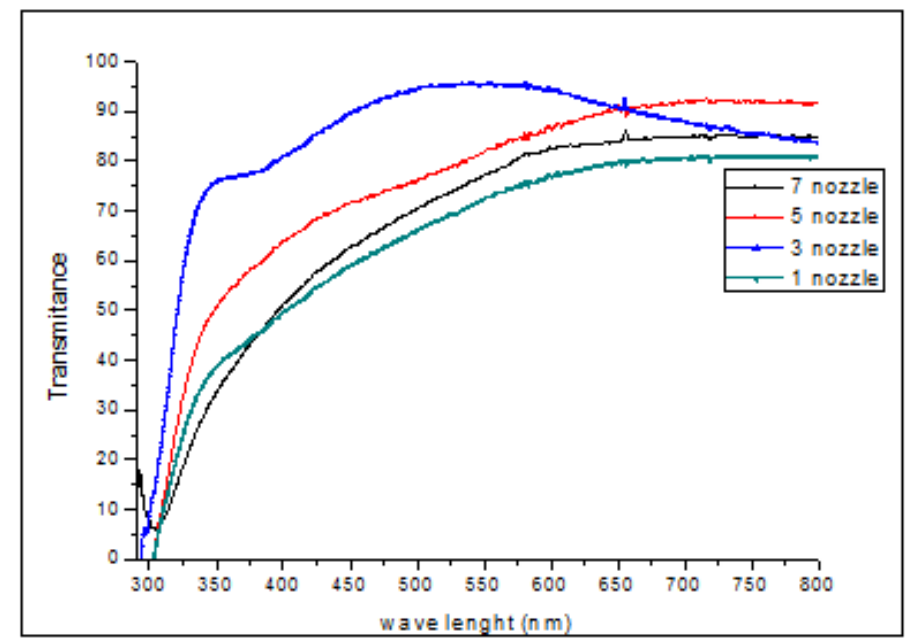

Figure 3. Optical transmittance for $\mathrm{SnO}_{2}$ films for a different nozzle

The theory of optical absorption gives the relationship between absorption coefficient $(\alpha)$ and the photon energy $h v$ [29,30]:

$$
\propto=\frac{B(h v-E g)^{2}}{h v}
$$

where $B$ is a constant, $E g$ is the optical band gap, $h$ is the Planck's constant, $x=0.5$ for the directly allowed transitions, and $\alpha$ can be calculated from the transmission spectrum using $\left(\propto=\frac{1}{d} \ln \frac{1}{t}\right)$ Then the incident photon energy is related to the direct band gap Eg by equation:

$$
(\alpha h v)^{2} \alpha(h v-E g)
$$

The $E g$ values were obtained by extrapolating the linear part of the plot of $(\alpha h v)^{2} v s$. $h v$ to $\alpha=0$, as shown in Fig.(4). The values of the energy gap are significantly decreased from $3.89 \mathrm{eV}$ to $3.6 \mathrm{eV}$ with the increase of the number of capillary tube from 1 to 7 . This may be ascribed to an effect of change in the grain size of polycrystalline films.

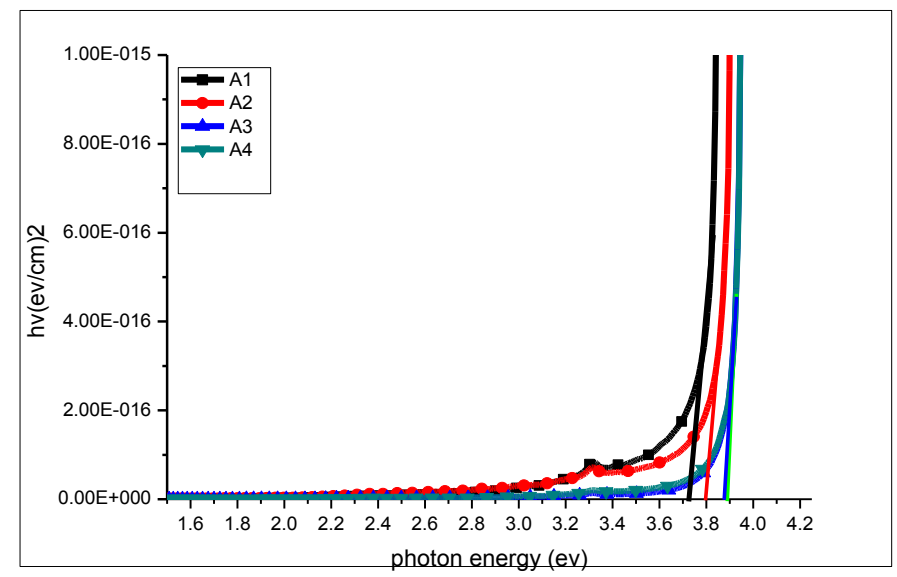

Figure 4. The variation of $(\alpha \mathrm{h} v) 2 \mathrm{vs.} \mathrm{h} v$ for determining the direct band gap Eg of the APCVD coated $\mathrm{SnO} 2$ films for a different nozzle. 


\section{IV.CONCLUSION}

In this work, a facile and simple APCVD technique was successfully used to deposit $\mathrm{SnO}_{2}$ thin films. We studied the effect of the number of capillary tube (different nozzle) on the structural and optical properties of the deposited samples. Surface roughness decreases from $1.81 \mathrm{~nm}$ to $0.259 \mathrm{~nm}$ with increasing no. of capillary tube. The transparency increases with the number of capillary tubes and then decreases with the use of seven capillary tubes and the optical band gap of the films are decreased by increasing the number of capillary tubes.

\section{REFERENCES}

[1] B Thangaraju, Thin Solid Films 402, 71 (2002)

[2] S.M.Sabnis, Prakash A. Bhadane, P. G. Kulkarni" Feasibility Study of New Techniques: Spray Pyrolysis Simulation",International Journal of Scientific \& Engineering Research, Volume 4, Issue 7, July-2013.

[3] Gotzberger A. and Hebling C.," Photovoltaic materials, past, present, future.Sol",EnergyMater.And Solar Cells, 1(62), 2000.

[4] Dr.Alaa A. Abdul- Hamead,"Study of Some properties of SnO2thin film",Eng. And Tech. Journal, vol.31, part A, No.12, 2013.

[5] Nomura K., Ujihira Y. and Sharma S S, Gas sensitivity of metal oxide mixed tin

[6] E Elengovan and K Ramamurthi, J. Optoelectron. Adv. Mater. 5/1, 45 (2003)

[7] W Y Chung, C H Shim, S D Choi and D D Lee, Sens. Act. B20, 139 (1994)

[8] B Thangaraju, Thin Solid Films 402, 71 (2002)

[9] J R Brown, P W Haycock, L M Smith, A C Jones and E W Williams, Sens. Act. B63, 109 (2000)

[10] P Nelli, G Faglia, G Sberveglieri, E Cerede, G Gabetta, A Dieguez and J R Morante, Thin Solid Films 371, 249 (2000)

[11] I Stambolova, K Konstantinov and T Tsacheva, Mater. Chem. Phys. 63, 177 (2000)

[12] M Ruske, G Brauer and J Szczrbowski, Thin Solid Films 351, 146 (1999)

[13] Q Zhao, S Wu and D Miao, Adv. Mater. Res. 150-151, 1043 (2011)

[14] D Belanger, J P Dotelet, B A Lombos and J I Dickson, J. Electrochem. Soc. 398, 1321 (1985)

[15] A C Arias, L S Roman, T Kugler, R Toniola, M S Meruvia and I A Hummelgen, Thin Solid Films 371, 201 (2000)

[16] P S Shewale, S I Patil and M D Uplane, Semicond. Sci. Technol. 25, 115008 (2010)

[17] O K Varghese and L K Malhotra, J. Appl. Phys. 87, 7457 (2000)

[18] M K Karanjai and D D Gupta, J. Phys. D: Appl. Phys. 21, 356 (1988)

[19] G Gordillo, L C Moreno, W de la Cruz and P Theran, Thin Solid Films 252, 61 (1994)

[20] A Malik, A Seco, E Fortunato and R Martin, J. Non-Cryst. Solids 1092, 227 (1998)

[21] B Zhang, Y Tian, J C Zhang and W Cai, J. Mater Sci. 46, 1884 (2011)

[22] A V Moholkara, S M Pawara, K Y Rajpureb, S N Almaric, P S Patilb and C H Bhosale, Solar Energy Mater. Solar Cells 92 , 1439 (2008)

[23] G Frank, E Kaur and H Kostlin, Sol. Energy Mater. 8, 387 (1983)

[24] S U Lee, W S Choi and B Hong, Phys. Scr. T129, 312 (2007)

[25] Q Chen, Y Qian, Z Chen, G Zhou and Y Zhang, Thin Solid Films 264, 25 (1995)

[26] A Smith, J M Laurent, D S Smith, J P Bonnet and R R Clemente, Thin Solid Films 266, 20 (1995)

[27] K Omura, P Veluchamy and M Murozono, J. Elecktrochem. Soc. 146, 2113 (1999)

[28] A V Moholkar, S M Pawara, K Y Rajpure, C H Bhosale and J H Kim, Appl. Surface Sci. 255, 9358 (2009) oxide films prepared by spray pyrolysis. J.Mater. Sci., 937(24), 1989.5-Pan, S.S., C.

[29] El Sayed A M, Shaban M. (2015) Structural, Optical and Photocatalytic properties of Fe and (Co, Fe) co-doped Copper Oxide Spin Coated Films.Spectrochimica Acta Part A: Molecular and Biomolecular Spectroscopy. 149.pp. 638-646.

[30] Shaban M, El Sayed AM. (2015). influences of Lead and Magnesium co-doping on the Nanostructural, Optical properties and Wettability of Spin Coated Zinc Oxide Films. Materials Science in Semiconductor Processing . 39. Pp.136-147. 